\title{
Revisiting the Treatment Recommendations for Chronic Hepatitis B
}

\section{To the Editor:}

I read with great interest the work by Tong et al. ${ }^{1}$ on the evaluation of current treatment recommendations based on a longitudinal cohort of 369 chronic hepatitis B patients followed for a mean of 84 months. Under the published guidelines, in $2003-2007,40 \%$ to $80 \%$ of patients who developed hepatocellular carcinoma (HCC) or died of liverrelated problems did not fall into the criteria for antiviral treatment. The authors have proposed adding low platelet count and low serum albumin to the guidelines so that up to $100 \%$ of patients who develop HCC or die can be identified. I have a different angle of interpretation on the results of this study.

Low platelet count and low serum albumin are surrogate markers of portal hypertension and hepatic dysfunction, respectively. Patients who have these laboratory findings are likely suffering from early liver cirrhosis. In the report by Tong et al., ${ }^{1}$ five of nine patients who developed HCC were diagnosed as having chronic hepatitis by histology and therefore did not fulfill the recommended treatment criteria. These patients probably had normal alanine aminotransferase (ALT) and/or intermediate hepatitis B virus (HBV) DNA levels (between 10,000 and 100,000 copies/mL). This observation revealed the insufficiency of liver biopsy in determining the true liver histologic staging, particularly when the biopsy core is not long enough. ${ }^{2}$ It would be interesting to know the length and number of portal tracts of the liver biopsies among patients with histologic chronic hepatitis in this report. Furthermore, $5 \%$ to $18 \%$ of hepatitis $\mathrm{B}$ e antigen-negative chronic hepatitis B patients with normal ALT $(<30$ IU/L in men and $<19$ IU/L in women) might already have developed liver cirrhosis. ${ }^{3}$

In the current report, ${ }^{1} 7$ of 15 patients with cirrhosis who developed HCC could not be identified by the treatment recommendations. The reason for missing these patients was most likely their low HBV DNA levels (lower than 10,000 copies/mL). Previous large-scale longitudinal studies have confirmed that HBV DNA and liver cirrhosis are independent risk factors of HCC. ${ }^{4,5}$ In other words, patients with cirrhosis have a significant risk of developing HCC even when their HBV DNA levels are not high. In the cohort studied by Tong et al., two-thirds of the patients who had HBV DNA levels lower than 10,000 copies $/ \mathrm{mL}$ in fact had HBV DNA levels lower than 1000 copies $/ \mathrm{mL}$. The number of patients with cirrhosis who had undetect- able HBV DNA but developed HCC on subsequent follow-up was not reported. It remains dubious whether antiviral treatment can reduce the risk of liver-related complications in patients with cirrhosis with very low viremia.

In summary, to improve current treatment recommendations, high-quality liver biopsy of adequate length should be encouraged when there is clinical suspicion of liver cirrhosis (e.g., middle-age patients with low platelet count and/or low serum albumin), regardless of the ALT and HBV DNA levels. Antiviral treatment should be recommended for all patients with cirrhosis with detectable HBV DNA in order to maximize the possible benefit of treatment.

\section{HENRY L. Y. CHAN \\ The Chinese University of Hong Kong Hong Kong SAR, China}

\section{References}

1. Tong MJ, Hsien C, Hsu L, Sun HN, Blatt LM. Treatment recommendations for chronic hepatitis B: an evaluation of current guidelines based on a natural history study in the United States. Hepatology 2008;48:10701078.

2. Bedossa $P$, Dargère $D$, Paradise V. Sampling variability of liver fibrosis in chronic hepatitis C. Hepatology 2003;38:1449-1457.

3. Wong GLH, Wong VWS, Choi PCL, Chan AWH, Chim AML, Yiu $\mathrm{KKY}$, et al. Evaluation of alanine transaminase and hepatitis $\mathrm{B}$ virus DNA to predict liver cirrhosis in hepatitis $\mathrm{B}$ e antigen-negative chronic hepatitis $\mathrm{B}$ using transient elastography. Am J Gastroenterol. In press.

4. Chan HLY, Tse CH, Mo F, Koh J, Wong VWS, Wong GLH, et al. High viral load and hepatitis B virus subgenotype Ce are associated with increased risk of hepatocellular carcinoma. J Clin Oncol 2008;26:177-182.

5. Chen CJ, Yang HI, Su J, Jen CL, You SL, Lu SN, et al. Risk of hepatocellular carcinoma across a biological gradient of serum hepatitis B virus DNA level. JAMA 2006;295:65-73.

Copyright () 2008 by the American Association for the Study of Liver Diseases. Published online in Wiley InterScience (www.interscience.wiley.com).

DOI 10.1002/hep.22714

Potential conflict of interest: Dr. Chan advises Bristol-Myers Squibb, Novartis, Schering-Plough, and PharmaNess.

\section{Do Guidelines Preclude Hepatitis B Patients from Receiving Treatment?}

\section{To the Editor:}

We read with great interest the article by Tong et al. ${ }^{1}$ in the October 2008 issue of Hepatology.

In this article, the authors determined whether the four published guidelines/algorithm (European Association for the Study of the Liver, American Association for the Study of Liver Diseases, Asian Pacific Association for the Study of the Liver, and US Panel) on hepatitis B treatment correctly identified for treatment patients who subsequently developed hepatocellular carcinoma (HCC) or suffered non-HCC liver-related deaths. Tong et al. retrospectively analyzed the outcome of 369 hepatitis B surface antigen ( $\mathrm{HBs} A$ ) - positive patients followed for a mean of 7 years, and they reported that if the criteria for antiviral therapy stated in the current treatment guidelines/algorithm had been used, only $20 \%$ to $60 \%$ of the patients who developed HCC and $27 \%$ to $70 \%$ of the patients who suffered non-HCC liver-related deaths would have been identified for antiviral therapy. The authors found that the addition of baseline serum albumin, platelet count, and presence of basal core promoter and precore mutations would improve the accuracy of the identification of these patients to $90 \%$ to $100 \%$. The authors concluded that if current guidelines were used, a significant proportion of HBsAg-positive patients would be deprived of the possible benefits of antiviral therapy.

However, the results of this and other studies on this topic ${ }^{2}$ need to be interpreted carefully. First, all guidelines recommend that patients who are not initiated on treatment should continue to be monitored and that treatment should be initiated later when the indications arise. ${ }^{3}$ In this study, the authors focused on laboratory test results at the first visit and did not consider the option of treatment after an initial period of observation. As the authors indicated, alanine aminotransferase (ALT) levels fluctuated during follow-up. Thus, many of the patients would have met treatment criteria at some point during the course of follow-up. Second, $78.5 \%$ of the patients were Asians and likely acquired hepatitis B virus (HBV) infection perinatally or during early childhood. The mean age of the patients at recruitment was 48 years, 
indicating that most of the patients had been infected for more than 4 decades. In light of recent findings that persistently high serum HBV DNA is a predictor of clinical outcomes and significant liver disease may be present in patients with normal ALT, the 2007 American Association for the Study of Liver Diseases practice guidelines recommended that lower HBV DNA and ALT cutoffs be applied to patients older than 40 years and liver biopsies be performed in patients with HBV DNA and ALT values in the grey zone. ${ }^{3}$ Finally, the authors assumed that had antiviral treatment been administered at presentation, all cases of HCC and liver-related mortality would have been prevented. Clinical studies have shown that antiviral therapy is not effective in improving survival for patients with advanced liver failure. ${ }^{4}$ Moreover, antiviral therapy decreases but does not completely prevent the risk of HCC. 5,6

We congratulate the authors for conducting this study. However, we caution readers that decisions on hepatitis B treatment should not be based solely on laboratory test results at the first visit. Given the fluctuating nature of chronic HBV infection, all patients should be monitored for life so treatment can be initiated later when the indication arises.

\section{BULENT DEGERTEKIN \\ ANNA S. LOK \\ Division of Gastroenterology \\ University of Michigan Medical Center Ann Arbor, MI}

\section{References}

1. Tong MJ, Hsien C, Hsu L, Sun HE, Blatt LM. Treatment recommendations for chronic hepatitis B: an evaluation of current guidelines based on a natural history study in the United States. Hepatology 2008;48:10701078.

2. Kumar M, Sarin SK, Hissar S, Pande C, Sakhuja P, Sharma BC, et al. Virologic and histologic features of chronic hepatitis B virus-infected asymptomatic patients with persistently normal ALT. Gastroenterology 2008;134:1376-1384.

3. Lok AS, McMahon BJ. Chronic hepatitis B. Hepatology 2007; 45:507539.

4. Fontana RJ, Hann HW, Perrillo RP, Vierling JM, Wright T, Rakela J, et al. Determinants of early mortality in patients with decompensated chronic hepatitis B treated with antiviral therapy. Gastroenterology 2002; 123:719-727.

5. Villeneuve JP, Condreay LD, Willems B, Pomier-Layrargues G, Fenyves $\mathrm{D}$, Bilodeau $\mathrm{M}$, et al. Lamivudine treatment for decompensated cirrhosis resulting from chronic hepatitis B. HEPATOLOGY 2000;31:207-210.

6. Liaw YF, Sung JJ, Chow WC, Farrell G, Lee CZ, Yuen H, et al. Lamivudine for patients with chronic hepatitis $\mathrm{B}$ and advanced liver disease. N Engl J Med 2004;351:1521-1531.

Copyright (C) 2008 by the American Association for the Study of Liver Diseases. Published online in Wiley InterScience (www.interscience.wiley.com). DOI 10.1002/hep.22722

Potential conflict of interest: Dr. Lok is a consultant for and received grants from Gilead and Schering-Plough. She is also a consultant for Roche and received grants from Bristol-Myers Squibb, GlaxoSmithKline, and Novartis.

\section{Reply:}

We thank Tilmann et al., ${ }^{1}$ Chan, ${ }^{2}$ and Degertekin and Lok $^{3}$ for their thoughtful comments and questions concerning our article. ${ }^{4}$ As they clearly point out, the decision to treat a patient with chronic hepatitis B according to guidelines remains controversial, and ultimately, the final choice to treat an individual patient should be based on inclusion in the guideline criteria along with the clinical judgment of the physician. As many of the guideline criteria are now being reevaluated, the letters by Chan and Tilmann et al. aptly raise the
Table 1. Distribution of Clinical Outcomes by the HBV DNA Category for Patients with Cirrhosis $(n=129)$

\begin{tabular}{llccc}
\hline $\begin{array}{l}\text { HBV DNA } \\
\text { Category }\end{array}$ & $\begin{array}{l}\text { Total: } \\
\mathbf{n}(\%)\end{array}$ & $\begin{array}{c}\text { Liver-Related } \\
\text { Death: } \mathbf{n}(\%)\end{array}$ & $\begin{array}{c}\text { Developed } \\
\text { HCC: } \mathbf{n}(\%)\end{array}$ & $\begin{array}{l}\text { Alive: } \\
\mathbf{n}(\%)\end{array}$ \\
\hline Negative & $21(16.3)$ & $6(16.2)$ & $5(23.8)$ & $10(14)$ \\
$\leq 10^{4}$ & $12(9.3)$ & $4(10.8)$ & $2(9.5)$ & $6(8.5)$ \\
$>10^{4}$ & $96(74.4)$ & $27(73)$ & $14(66.7)$ & $55(77.5)$ \\
\hline
\end{tabular}

Abbreviations: HBV, hepatitis B virus; HCC, hepatocellular carcinoma.

question of lowering the hepatitis B virus (HBV) DNA criteria in patients with cirrhosis to allow treatment in those patients who have detectable HBV DNA concentrations of $\leq 10^{4}$ copies $/ \mathrm{mL}$. The clinical outcomes of the 129 patients with cirrhosis in our database by qualitative HBV DNA categories (negative, $\leq 10^{4}$, and $>10^{4}$ ) are shown in Table 1. As shown in the table, six patients with cirrhosis who either died from a non-hepatocellular carcinoma (HCC) liver-related event or who developed HCC had detectable baseline HBV DNA concentrations that were $\leq 10^{4}$ copies $/ \mathrm{mL}$. However, 11 patients had HBV DNA levels below the limit of detection and either died from a liverrelated event or developed HCC. Thus, modification of the treatment guidelines to include patients who have detectable baseline HBV DNA concentrations of $\leq 10^{4}$ copies $/ \mathrm{mL}$ would have captured patients from our database who ultimately had a poor outcome but would not have addressed those patients who presented with HBV DNA concentrations below the limit of detection. It is important to note, as the three letters point out and as we mentioned in the discussion section of our original article, that further prospective treatments trials are required to determine if antiviral therapies will have any impact on the incidence of HCC, especially in patients with less active liver disease [i.e., low or undetectable levels of viremia and normal or nearly normal alanine aminotransferase (ALT) levels].

The letter by Tilmann et al. ${ }^{1}$ also suggests that the use of more recently developed guidelines, such as those published by Cornberg et al., 5 may have captured additional patients with poor prognosis who were not recommended for treatment by the original four guidelines assessed in our article. ${ }^{4}$ To address this question, we conducted an analysis of patients in our database using the criteria established by Cornberg et al. The initial recommendation by Cornberg et al. is to treat all patients with cirrhosis who have detectable HBV DNA. As shown in Table 1, use of these criteria would have captured the six patients who had a poor outcome and presented with baseline HBV DNA levels of $\geq 10^{4}$ but would have excluded the 11 patients with a poor prognosis who presented with HBV DNA levels below the detectable limits. Although we agree that the utility of treatment of patients with cirrhosis and serum HBV DNA levels below the detectable limits remains unknown, it is important to point out that patients who have serum HBV DNA levels below the detectable limit of the assay still may have underlying HBV DNA replication at low levels and may benefit from antiviral therapy.

The application of Cornberg et al.'s criteria ${ }^{5}$ to the population of patients without cirrhosis in our database would have captured the nine patients who developed HCC and were not identified by the original European Association for the Study of the Liver, US Panel, Asian Pacific Panel, or American Association for the Study of Liver Diseases guidelines as candidates for therapy. In our database, ${ }^{4}$ nine patients without cirrhosis who were excluded from antiviral therapy by at least one of the guidelines eventually developed HCC. Cornberg et al.'s criteria initially assess patients without cirrhosis by baseline serum HBV DNA concentrations and recommend therapy in those patients who have serum HBV DNA concentrations of $>10^{4}$ copies $/ \mathrm{mL}$ and who also meet subsequent ALT, liver histology, and HCC risk factor criteria. All nine patients who were noncirrhotic and developed HCC and who were excluded from treatment by at least one guideline had a baseline serum HBV DNA concentration of $>10^{4}$ copies $/ \mathrm{mL}$. Of the 